\title{
El sublime objeto de los Incas: la colección de Susana Torres
}

\section{The sublime object of the Incas: the Susana Torres collection}

\author{
Víctor Vich \\ Pontificia Universidad Católica del Perú
}

Fecha de recepción: 22 de noviembre de 2020

Fecha de aceptación: 19 de septiembre de 2021

\author{
Anuario del Departamento de Historia y Teoría del Arte \\ vol. 33, 2021, pp. 101-115 \\ ISSN: 1130-5517, eISSN: 2530-3562 \\ https://doi.org/10.15366/anuario2021.33.005
}

\begin{abstract}
RESUMEN
Este ensayo estudia una colección de distintas mercancías que se encentran agrupadas por llevar consigo la palabra "Inca" (o "Inka"). A partir de la teoría del "inconsciente político" propuesta por Jameson, el argumento sostiene que nos encontramos ante la conversión de la historia en un simulacro, pero, también, ante el intento de restaurar una condición utópica de la historia que sigue entendiéndose como central. Desde el gesto iconoclasta que retoma la vieja herencia de la vanguardia, la colección muestra una tensión nunca resuelta dentro y fuera del sistema del arte. En última instancia, el "Museo Neo Inka" subraya la producción de una mirada capaz de re-auratizar falsos semblantes utópicos en la actual vida peruana.
\end{abstract}

\section{PALABRAS CLAVE}

Susana Torres. Arte peruano contemporáneo. Incas. Museotopía.

\begin{abstract}
This essay studies a collection of different goods that are grouped together because they carry the word "Inca" (or "Inka"). Based on the theory of the "political unconscious" proposed by Jameson, the argument argues that we are faced with the conversion of history into a simulacrum, but also with the attempt to restore an utopian condition of history that continues to be understood as central. From the iconoclastic gesture that takes up the old heritage of the avant-garde, the collection shows a tension never resolved inside and outside the art system. Ultimately, the "Museo Neo Inka" underscores the production of a gaze capable of re-auratizing false utopian semblances in current Peruvian life.
\end{abstract}

\section{KEY WORDS}

Susana Torres. Contemporary Peruvian Art. Incas. "Museotopía". 
"La tierra, plenamente mercantilizada, irradia un desastre triunfante".

Theodor Adorno y Max Horkheimer

El "Museo Neo Inka" de la artista Susana Torres es una de las colecciones (¿de arte?) que permite pensar el estatuto del objeto artístico, de la imagen y de la historia peruana (o quizá de la historia "a secas") en el contexto de un momento del desarrollo de la modernidad que ha sido caracterizado por su pérdida del sentido de la historicidad ${ }^{1}$. Esta colección, que reúne muchísimos objetos de consumo que utilizan la palabra "Inca" (o "Inka") como gancho comercial, cuenta con centenares de piezas y anda siempre incrementándose, aunque debido a lo perecible de algunas de ellas, también va sufriendo algunas pérdidas. Por un lado, esta colección puede ser entendida, bajo la herencia de Duchamp, como una especie de "ready made" que juega con los límites del arte y que busca problematizar la definición misma del hecho artístico, pero por otro, puede interpretarse como una puesta en escena destinada a mostrar la vocación cosificadora del capitalismo que utiliza el pasado para legitimarse y convertirlo en un fetiche ${ }^{2}$.

Gustavo Buntinx ha llamado "museotopías" a un conjunto de prácticas que subvierten la idea de la colección -y de la entidad que la acoge- desde intereses diversos que van más allá de los propiamente establecidos por el sistema del arte. Proyectos como estos comenzaron a aparecer en el Perú a principios de la década de 1980 y fueron parte del debate sobre el arte contemporáneo tanto en la escena local como internacional ${ }^{3}$. Estas "museotopías" se adentran en imaginarios que están latentes en la cultura y que andan buscando formas y canales para manifestarse pues se trata de narrativas reprimidas que pugnan por hacerse visibles a fin de intervenir en la esfera pública. En realidad, los objetos reunidos en las museotopías no son necesariamente "arte" (no han sido producidos como tales), pero, al interior de ellas, parecen destinados a activar intensos significados conceptuales, estéticos y políticos ${ }^{4}$.

El "Museo Neo Inka" es una de estas colecciones (y conceptos). Su caso es complejo porque reúne objetos producidos por el mercado y para el mercado, es decir, objetos que solo pueden adquirirse en las tiendas. Como en toda colección, el gesto ha consistido en sacar a esos objetos de su circulación, vale decir, de interrumpir su valor de cambio, para mostrar el estatuto de su significante y, desde ahí, exigir una nueva mirada. De hecho, para ser parte de la colección, el requisito es que la marca del producto incorpore la palabra "Inca" (o "Inka"). Desde ahí, el objetivo consiste en hacer visible la iconización consumista que se legitima en el mercado apelando a un pasado utópico, vale decir, a los significados positivos (y hasta mesiánicos) que tal

\footnotetext{
${ }^{1}$ Fredric Jameson, El posmodernismo o la lógica cultural del capitalismo tardio (Barcelona: Paidós, 1992).

2 Hasta el momento la colección se ha presentado once veces. Museo Neo Inka I. El retorno de los Inkas (no retornables). Galería John Harriman, Asociación Cultural Peruano-Británica. Lima. 1999; Museo Neo Inka II Segunda Bienal Nacional. Lima, Perú. 2000; Museo Neo Inka III fue parte de la muestra colectiva: Necrología, El Retorno de las Huacas (no retornables) 19772003, Museo de Osma 2003; Museo Neo Inka IV fue parte de: IV Passeport Pour un Artiste. Concurso de Artes Visuales de la Embajada de Francia. Sala del Centro Cultural de la Universidad Católica. PUCP. Lima 2003; Museo Neo Inka V. El Repase. Muestra Antológica de Susana Torres 1992-2007. Sala Raúl Porras Barrenechea. Lima. 2007; Museo Neo Inka VI fue parte de la muestra: Mali contemporáneo. Adquisiciones y donaciones 2007, Museo de Arte de Lima (MALI), 2007; Museo Neo Inka VII fue parte de: Passeport Pour un Artiste, exposición de aniversario con los mejores trabajos a través de los años, 2008. Sala Raúl Porras Barrenechea, Lima; Museo Neo Inka VIII fue parte de la muestra: Lo impuro y lo contaminado III, Museo de Arte Contemporáneo de Chile, MAC. Primera Trienal de Chile, Santiago de Chile, 2009; Museo Neo Inka I Re-decorando la Huaca, Sala Luis Miro Quesada Garland, Lima, 2014; Museo Neo Inka X. Arma tu propio Imperio, instalación de fragmento de museo en la Feria Internacional de Arte, Art Lima, Lima, 2014; Museo Neo Inka XI. Trono Inka o trono de la Inka, instalación de fragmento de museo en la gran muestra Comparart, Museo de la Nación, Lima, 2016.

${ }^{3}$ En la escena latinoamericana, puede destacarse el llamado "Museo Salinas" de Vicente Razo. A nivel teórico, pueden consultarse los trabajos de Márcio D’Olne Campos, "Symbolic courses of cultural objects: collecting, exhibition and the counter metaphor". Boletim do Museu Paraense Emilio Goeldi: Ciências Humanas 7, n. ${ }^{\circ} 1$ (abril 2012): 95-109, https://doi.org/10.1590/ S1981-81222012000100009.

4 Gustavo Buntinx, "Museotopías: tres textos utópicos sobre el vacío museal en el Perú", en Micromuseo 0 (Lima: Micromuseo), 2001, 3-13.
} 
nombre activa en el imaginario nacional ${ }^{5}$. Si, en la actualidad, algunos procesos de modernización intentan, a toda costa, desprenderse de los restos de indigenidad existente, lo cierto es que la palabra "Inca", en el Perú, todavía conserva un enorme prestigio y continúa remitiendo no solo a lo perdido sino además a lo entrañablemente propio ${ }^{6}$. Desde este punto de vista, podemos sostener que esta colección muestra la mercantilización terminal de la historia peruana, pero es también un dispositivo que activa fantasías de deudas y resarcimientos.

Interesa, por tanto, reflexionar sobre esta "museotopía" en tanto en ella es posible observar no solo el viejo problema sobre cómo cualquier objeto puede iniciar una colección o, más aún, llegar a ser parte de la historia del arte, sino cómo, su especial curadoría, se propone activar una nueva mirada sobre la producción de mercancías, sobre el sistema del arte y, sobre todo, sobre la historia peruana.

Historiemos un poco y expliquemos que el origen del "Museo Neo Inka" surgió de una "simple nostalgia sensorial" según me lo comentó la propia artista. En realidad, surgió de una burla que pronto se volvió autorreflexiva. Por algunos años, Susana Torres vivió de manera intermitente en Buenos Aires y no solo notó la cantidad de peruanos que habían migrado hacia la Argentina, sino además constató cómo el mercado producía para ellos un sinnúmero de "canastas de la añoranza" (según su expresión) que agrupaban un conjunto de comestibles típicos del consumo nacional: panetón D'Onofrio, chocolates Sublime, caramelos Cocorocos y, por supuesto, Inca Kola. Los peruanos, residentes en la Argentina, las compraban a fin de neutralizar las nostalgias del exilio o de la pura emigración desesperada.

Poco después, vivió seis meses en Austin, en los Estados Unidos, y allá, en la lejana Texas, también observó la misma ansiedad por los productos peruanos, al punto que una noche, en la casa de un compatriota, muerta de sed, abrió la refrigeradora, encontró la bebida amarilla (“The Golden Kola”) y comenzó a tomársela con verdadera emoción. No habían pasado muchos minutos hasta que su amigo la descubrió y le increpó bruscamente: “¡Te estás tomando mi Inca Kola!”, le dijo, molesto, como si efectivamente dicha lata fuera la última bebida del desierto.

El punto es que Susana Torres me contó que ella también se fue volviendo adicta a los productos peruanos y, especialmente, a la "bebida del sabor nacional". "Sin darme cuenta, pasé de la burla a la necesidad", me dijo claramente. La inicial ironía sobre el "comercio de la nostalgia" pronto revertió sobre sí misma. Por eso mismo, en medio de estas ansiedades y melancolías, comenzó a acopiar las diferentes botellas de Inca Kola y, con ellas, a todos aquellos productos que llevaran la palabra Inca (o Inka) como su marca comercial. Se le ocurrió entonces construir una colección que pudiera ser expuesta en un contexto de arte. De hecho, ella era ya una artista conocida en el medio plástico local. Sus trabajos visuales, sus distintas performances y su interés por los ready-mades colocaban a su obra como una de los más interesantes en la escena peruana desde mediados de la década del noventa7. Una vieja pregunta dadaísta (que ella se hizo a sí misma) revela bien no solo las características del proyecto que comenzaba a ponerse en curso sino también del lugar del arte en la cultura actual o, mejor dicho, la condición del objeto artístico en una sociedad permanentemente reificada por el fetichismo de la mercancía: "¿Para qué voy a producir obra si lo único que tengo que hacer es irme de compras?", se dijo a sí misma, sin nada de culpa.

A fin de comenzar a construir una interpretación del "Museo Neo Inka" partamos recordando la muy conocida afirmación que, en 1867, sostuvo que la riqueza de la sociedad contemporánea se presenta como un "enorme

\footnotetext{
5 Alberto Flores Galindo, Buscando un inca. Identidad y utopía en los andes (Lima: Horizonte, 1988); Manuel Burga, Nacimiento de una utopía. Muerte y resurrección de los incas (Lima: Instituto de Apoyo Agrario, 1988).

${ }^{6}$ El retorno de símbolos de los incas puede rastrearse al menos desde el siglo XVIII en el que se ha notado la presencia de un movimiento intelectual nacionalista que sirvió de germen para muchas rebeliones anticoloniales. Desde entonces muchos caciques y criollos comenzaron a reapropiarse de símbolos incaicos (en la vestimenta, en los tejidos y en la cerámica) para cuestionar el presente y difundir la autoridad (idealizada) del pasado: John Rowe, "El movimiento nacional inca del siglo XVIII" en Túpac Amaru II, 1780. Antología (Lima: Retablo de papel ediciones, 1976), 13-66. Recientemente, Ramón Mujica ha publicado Arte imperial inca: sus orígenes y transformaciones desde la conquista a la independencia (Lima: Banco de Crédito del Perú, 2020).

7 El año 1990 formó parte del colectivo responsable de la histórica exposición Restauración / No restauración, en el Museo de Arte Italiano de Lima. Y en la galería Parafernalia de esa misma ciudad realizó dos exposiciones individuales: La Vandera (1995) y Tamatetita (1996). En 1997 fue especialmente invitada a la VI Bienal de La Habana, etc.
} 
cúmulo de mercancías" ${ }^{\text {y }}$ añadamos que el arte también se ha convertido en mercancía y que la propia mercancía se ha convertido en arte. De hecho, y desde hace un buen tiempo ya, lo económico parece "uno respecto de lo cultural" pues todo lo que compramos está tan culturizado por la publicidad que resulta difícil afirmar si estamos consumiendo una imagen o un objeto material". Dejemos, sin embargo, este tema para más adelante y enumeremos el tipo de piezas atesoradas por esta colección que acoge elementos como cigarros, latas de atún, bolsas de cemento, sobres de té, harina de trigo, sal yodada, latas de durazno, muñecas "Barbie" (confeccionadas nada menos que por la propia casa Mattel, en su modelo "Princess of the Incas"), entre muchos más.

Una mirada detenida podría localizar al menos diez rubros. Los enumero aquí: 1) Una serie de botellas históricas de Inca Kola; 2) Comestibles diversos; 3) Otras mercancías pertinentes; 4) Parafernalia comercial de dichos productos (artículos contables y publicitarios, envolturas, papelería y documentos en general, etc.); 5) "Antigüedades" comerciales (por lo general, donaciones de otros artistas y demás cómplices, que Torres denomina "arqueólogos de lo contemporáneo"); 6) Fotografías varias; 7) Registros de performances sobre el tema; 8) Registros de piezas de arquitectura efímera (en las últimas muestras la artista ha construido "huacas modernas" con ladrillos y cemento marca "Inca"); 9) Memorabilia de Yma Sumac (icono hollywoodense de la "incanidad", y de lo que Torres considera el "travestismo moderno" de esa categoría); 10) Obra plástica sobre el tema (donde destaca, por ejemplo, un gran autorretrato modelado en la efigie virreinal de una curaca que se hizo representar con atributos incaicos, a los que Susana añade una botella de Inca Kola) (figs. 1 y 2).

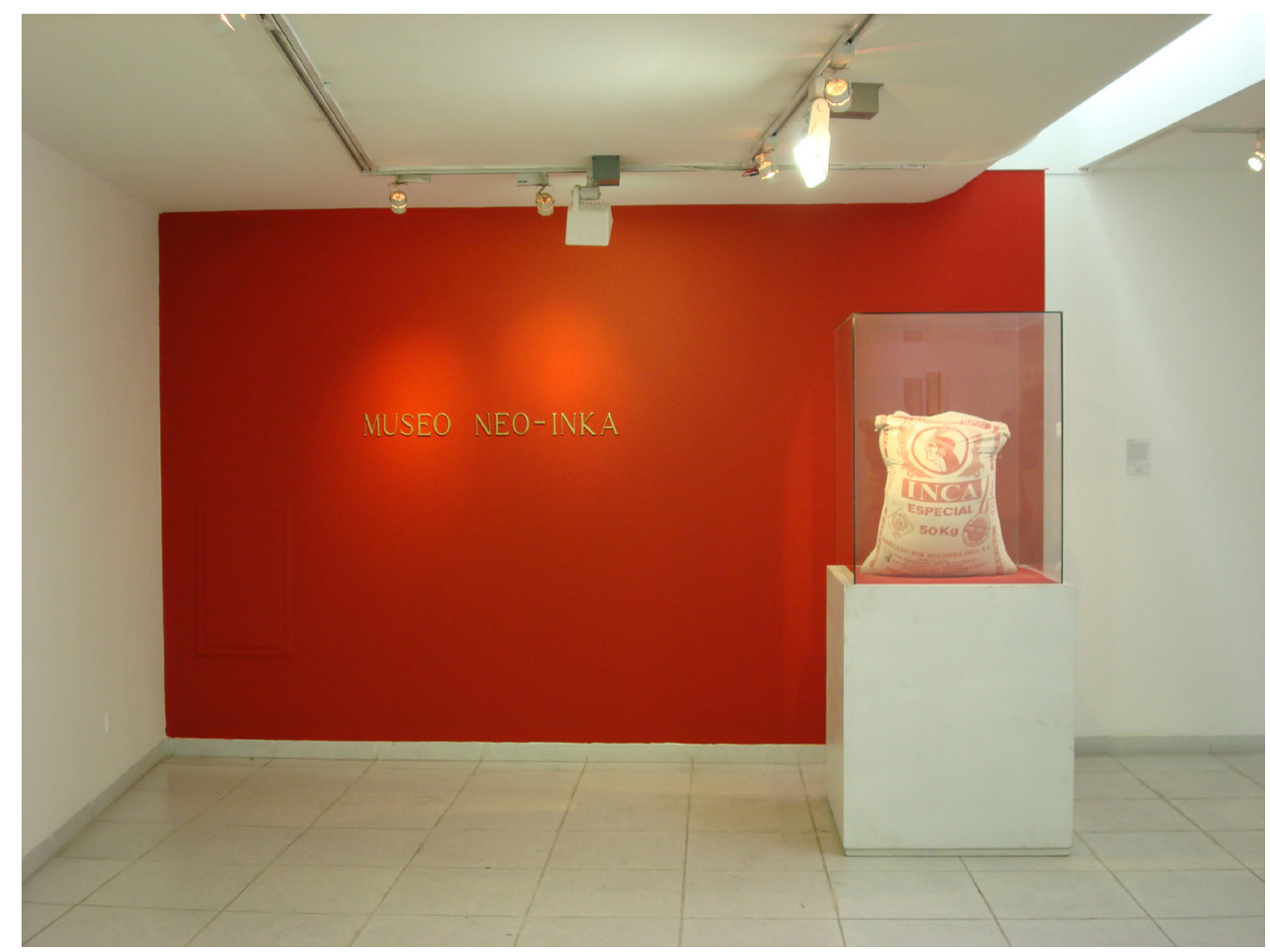

Fig. 1. Susana Torres Márquez, Museo Neo Inka VIII, 2003-2014. Costal de harina marca Inca, vitrina, letras de bronce, pared pintada de rojo (Reconstrucción del Museo Neo Inka IV, 2003, integrada a la exposición antológica del concurso Pasaporte para un Artista, Galería del Centro Cultural de la Pontificia Universidad Católica del Perú, Lima).

\footnotetext{
${ }^{8}$ Karl Marx. "El carácter fetichista de la mercancía y su secreto", en El Capital. Crítica de la economía política. Libro primero. El proceso de producción del capital (México D.F.: Siglo XXI, 1975), 43.

${ }^{9}$ Fredric Jameson, El postmodernismo revisado (Madrid: Abada editores, 2012), 23.
} 


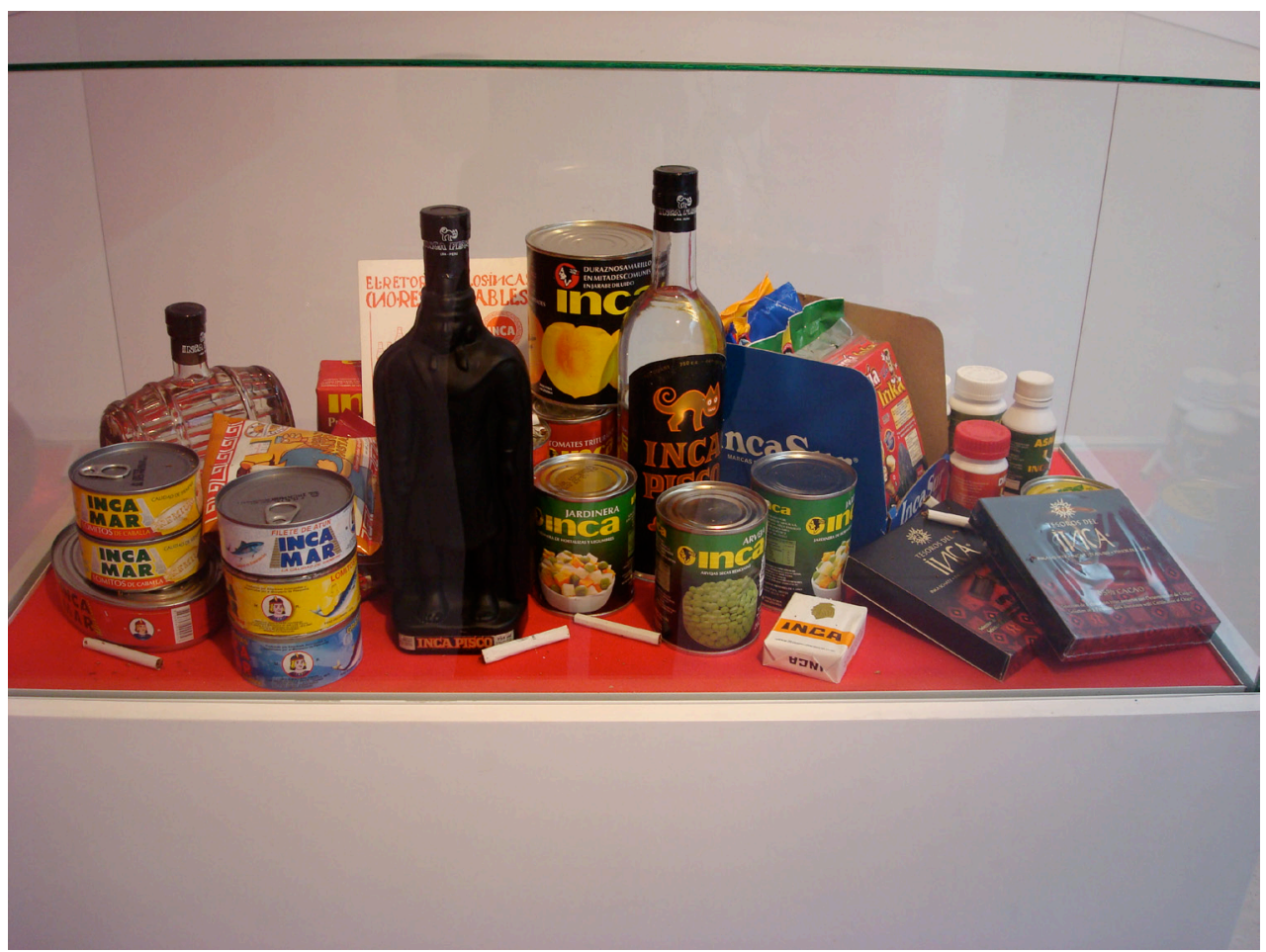

Fig. 2. Susana Torres Márquez, Bodegón Inka, 2007. Abarrotes varios con marcas alusivas a la palabra Inca, vitrina (Fragmento de la instalación Museo Neo Inka V, integrada a la exposición El repase. Muestra antológica de Susana Torres, 1992-2007, Centro Cultural Ricardo Palma, Lima).

Jameson ha insistido en la necesidad de producir una crítica cultural verdaderamente dialéctica que no le tenga miedo a la negatividad de las simultaneidades o paradojas ${ }^{10}$. Su propuesta invita a notar cómo todo objeto de la cultura de masas (por más "malo" o "frívolo" que sea) es siempre denso en significados pues trae consigo dos dimensiones contrapuestas. La primera dimensión, llamada "negativa", cumple una misión ideológica al legitimar una estructura de poder y generar formas de "falsa conciencia". En cambio, la segunda dimensión, llamada "positiva", es la encargada de activar un impulso utópico destinado a funcionar como resolución imaginaria de los antagonismos sociales. Jameson sostiene que es deber de la crítica ubicar ambas dinámicas y afirmarlas simultáneamente:

Las obras de la cultura de masas no pueden ser ideológicas sin ser, al mismo tiempo, implícita o explícitamente utópicas. No pueden manipular, a menos que ofrezcan algún genuino retazo de contenido como soborno para la fantasía del público que ha de ser manipulado. La angustia y la esperanza son dos caras de la misma conciencia colectiva, de modo que las obras de la cultura de masas, aun si su función radica en la legitimación del orden existente $-u$ otro peor-, no pueden realizar su tarea sin desviarse, al servicio del mismo, de las esperanzas y fantasías más fundamentales de la colectividad a la cual no importa de cuán retorcida manera se descubre que han dado expresión ${ }^{11}$.

Digámoslo de esta manera: para que un objeto de la cultura cumpla una función ideológica necesita, al mismo tiempo, ser utópico. Es decir, si queremos develar el "inconsciente político" que todo objeto cultural

${ }^{10}$ Fredric Jameson, "Reificación y utopía en la cultura de masas”, en: Signaturas de lo visible (Buenos Aires: Prometeo, 2012), 41-78.

11 Jameson, "Reificación y utopía", 71. 
trae consigo, debemos preguntarnos por el tipo de identificación imaginaria hacia el cual se dirige. Hoy, en efecto, la cultura de masas lo absorbe casi todo y sus mercancías, investidas siempre por el discurso publicitario, canalizan ciertas ansiedades sociales, activan formas de goce y procesan la historia de una manera muy peculiar a fin de generar, desde ahí, ciertos componentes utópicos que conviene comentar.

Desde ese punto de vista, son dos las interpretaciones sobre esta colección. La primera, construida a partir de una "hermenéutica negativa", sostendría que el "Museo Neo Inca" pone de manifiesto la conversión de la historia en un puro simulacro del mercado, vale decir, muestra la banalización terminal de la cultura peruana en su exotización postmoderna. La segunda interpretación, propuesta más bien desde una "hermenéutica positiva", observaría en ella el intento de restaurar una historia perdida que se sigue entendiendo como central a pesar de su ausencia. Con Jameson, podríamos decir que el "Museo Neo-Inka" muestra entonces una tensión no resuelta entre ambas dimensiones. Por un lado, es signo del carácter fetichista de la mercancía en su fase postmoderna, pero, por otro, subraya un tipo de pérdida histórica que activa la presencia de algún tipo de fantasía utópica.

Comencemos por la primera interpretación. En un capítulo muy importante de El Capital, Marx explicó cómo, bajo el capitalismo, un objeto asume tener ciertas características como si estas hubieran provenido del mismo objeto. Como sabemos, Marx describió al capitalismo como un sistema donde los objetos del trabajo humano se independizan de los hombres y se constituyen como un "poder exterior" que termina por someter a sus propios creadores. Estas dinámicas (que se deben a las relaciones sociales que lo produjeron) producen una extraña inversión en el que las cosas se personifican y las personas son tratadas como si fueran cosas. Por "fetichismo de la mercancía" se nombra tanto a una dinámica en la que el mercado invisibiliza las relaciones sociales que están detrás de la circulación, como al descubrimiento que, bajo el capitalismo, los sujetos terminan "sujetados" a un poder enajenado y enajenante.

Podemos sostener que el "Museo Neo-Inka" escenifica dimensiones de toda esta problemática y lo hace llamando la atención desde su forma misma. De hecho, todos estos productos asumen tener características que no poseen (no tienen nada que ver con la cultura Inca) pero se invisten de ello bajo un significante que se estetiza y que se carga de un valor. Notemos que ese mismo significante es, sin embargo, el encargado de ocultar una dimensión traumática de lo sucedido. Digamos entonces que, bajo la utilización de la palabra Inca (o "Inka"), la forma mercancía produce la ilusión de un país (más reconciliado consigo mismo) donde algo de ese pasado tiene vigencia y continúa presente (fig. 3). Si Marx había llamado la atención al señalar que el intercambio capitalista oculta la totalidad del funcionamiento del sistema, entonces debemos preguntarnos qué es lo que estos productos invisibilizan más allá del trabajo abstracto que los ha producido. Si hoy el fetichismo "se vincula al objeto-signo vaciado de su sustancia y de su historia, reducido al estado de marca de una diferencia" 12 , la repuesta no parece ser otra que lo invisibilizado aquí es la historia como ejercicio de poder y como dominación social.

Ahora bien, ¿cuál es la base social de este discurso?, ¿cuál es el contexto histórico de este tipo de apelación a la historia o al valor de la "incanidad"? De hecho, la actual apelación a lo Inca (o Inka) no corresponde ni a un amplio movimiento (cultural y político) como el que surgió en el siglo XVIII, como el que activó el indigenismo del siglo pasado o como el promovido por el gobierno militar a finales de la década de los sesenta. De hecho, estas imágenes no son expresión de movimientos sociales (o políticos) que les den sustento. Por eso, autores como Žižek sostienen que el multiculturalismo actual es, en realidad, la ideología oficial del capitalismo y que la actual apelación a la historia o a la diferencia cultural se encuentra muy lejos de cualquier tipo de demanda hacia una verdadera democratización socia ${ }^{13}$. En ese sentido, resulta claro que la producción de este tipo de imágenes solo está en función a promover un nuevo esencialismo cultural desvinculado de cualquier

\footnotetext{
12 Jean Baudrillard, Crítica de la economía politica del signo (México D.F.: Siglo XXI, 1974), 95.

13 Slavoj Žižek, "Multiculturalismo o la lógica cultural del capitalismo multinacional”, en Estudios Culturales. Reflexiones sobre el multiculturalismo, ed. Fredric Jameson y Slavoj Žižek (Buenos Aires: Paidós, 2003), 137-88.
} 
crítica al modo de producción dominante. Digámoslo de una manera más simple: si hoy el capitalismo ha conseguido tomar casi toda la realidad social, en estos objetos podemos notar cómo el pasado (y la historia misma) no han podido salvarse de sus dinámicas. Desde ahí, el "Museo Neo Inka" escenifica, de manera lúdica e iconoclasta, la cosificación de la historia convertida en imagen y simulacro. Lo que se oculta no son solo el trabajo y las relaciones sociales que lo estructuran, sino también la historia misma ya cosificada estéticamente.

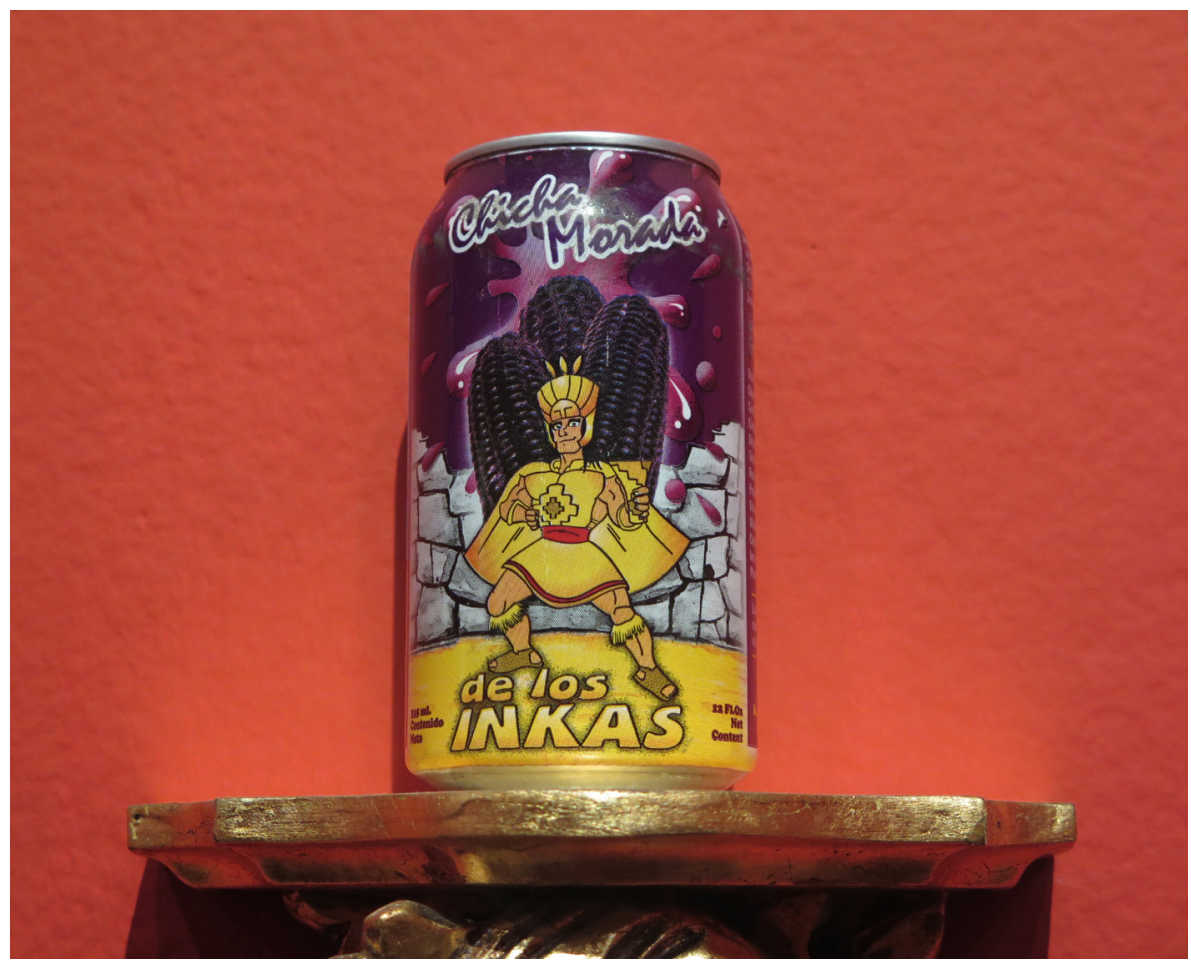

Fig. 3. Susana Torres Márquez, Objeto Neo Inka, 2009. Envase comercial de bebida marca Chicha Morada de los Inkas, repisa dorada (Fragmento de la instalación Museo Neo Inka VII, integrada a la exposición Lo Impuro y contaminado III: pulsiones (neo)barrocas en las rutas de Micromuseo, Trienal de Chile, Santiago).

Más aún, en este caso, el mercado se apropia de una dimensión ritual pues, de alguna manera, crea la ilusión de que tanto el objeto como el comprador quedan investidos de ese supuesto poder de "lo Inca" (o "Inka"). Es curioso porque sabemos que los incas perdieron, que fueron colonizados por los españoles y que su cultura fue desdeñada en distintos momentos de la historia peruana, pero, gracias a un calculado proceso de estetización, aquí sucede todo lo contrario. Desde una lógica puramente mercantil, hoy el significante "Inca" (o "Inka") ha pasado a simbolizar "calidad" y "fuerza" a pesar de su derrota histórica. Es la modernidad -que heredó y profundizó de la colonia la destrucción de lo Inca- la que hoy se apropia del significado prehispánico para dotarlo, curiosamente, de un aura de poder y eficacia. Podríamos decir entonces que lo que ocurre con la producción de estos objetos -y con la colección en general- es una especie de desconstrucción de la oposición Inca / modernidad, pues aquello que fue perdedor en el pasado, pero ciertamente victorioso en un pasado más pasado que el pasado (el periodo prehispánico), resurge con dignidad en el presente mediante una especie de brillo cosificado.

Es aquí donde podría emerger la segunda interpretación si, más allá de una hermenéutica negativa y de la lógica de la "falsa conciencia", retomamos la propuesta de Jameson de observar la dimensión 


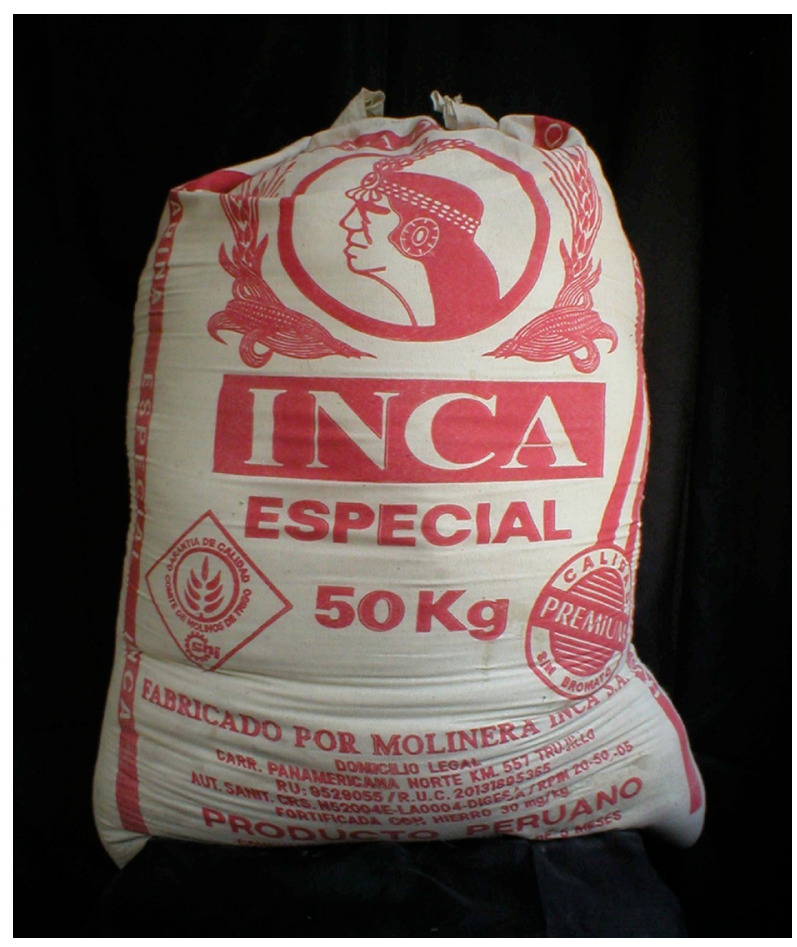

Fig. 4. Susana Torres Márquez, Fardo Inka, 1999. Costal de harina de trigo "especial Premium", marca Inca, $50 \mathrm{~kg}$. utópica que los productos culturales también traen consigo. Partamos de algunas preguntas: ¿son los objetos de esta colección la manifestación inconsciente de un impulso utópico que sigue buscando lugares insospechados para manifestarse?, ¿son ellos la terca presencia de un trauma histórico que intenta construir su autoridad desde un nuevo lugar? De hecho, el propio Marx nos invitó a detectar las relaciones sociales tras la apariencia autónoma de las cosas e insistió en redescubrir al hombre (y a su historia) tras la frialdad de los "valores de cambio". Insistamos con esta pregunta: ¿Más allá de la "cáscara cósica" de estos productos $^{14}$, es posible encontrar la presencia de un universo simbólico que intenta reinventarse y que busca nuevos espacios para actualizar diferentes irradiaciones políticas? (fig. 4).

El artista -y filósofo travesti- Giuseppe Campuzano, creador de otra importante "museotopía", sostuvo alguna vez que "toda peruanidad es un travestismo" y dicha idea resulta clave para entender el sentido de esta colección ${ }^{15}$. Me explico mejor: en un país que hasta principios del siglo XX procuraba negar sistemáticamente su herencia indígena (el Perú "se construyó sin el indio y contra el indio" sostuvo Mariátegui ${ }^{16}$ ) hoy es posible notar cómo, para poder sobrevivir, a la historia Inca solo le ha quedado la opción de "travestirse" en un producto comercial.

Sabemos bien que lo "Inca" es en Perú el signo de una herida en la historia. Este significante da cuenta de un imaginario asociado a la derrota, aunque es también capaz de activar, al mismo tiempo, una demanda de resarcimiento e igualdad. Si toda colección gira y se estructura ante un objeto que falta, entonces lo "Inca" es aquello que falta en el presente y es, desde ahí, que la pulsión utópica busca manifestarse ${ }^{17}$. Más allá de la objetividad espectral con la que este tipo de mercancías se presentan en el mercado, lo cierto es que ellas hacen presente algo del dramatismo de la historia como un incansable relato de pérdida y de posibilidad de redención.

14 Georg Lukács. "La cosificación y la consciencia del proletariado", en Historia y consciencia de clase (Madrid: Sarpe, 1984$), 16$.

15 Son importantes los vínculos artísticos entre Susana Torres y Giuseppe Campuzano, además de los vínculos curatoriales generados con Gustavo Buntinx. Tres museotopías se asociaron estrechamente: la del Museo Travesti del Perú (MTP), la del Museo Neo Inka (MNI) y la de Micromuseo. Esta última propició y acompañó textualmente la primera presentación pública del MTP: Gustavo Buntinx y Susana Torres, El signo carnal (Lima: Micromuseo, 2004), que después fue acogido por Micromuseo en las exposiciones Lo impuro y lo contaminado III -realizada el 2009 en el Museo de Arte Contemporáneo de Santiago durante la Trienal de Chile (https://www.micromuseo.org.pe/rutas/micromuseotrienal/index.html)- y Vacio museal: medio siglo de museotopías peruanas, presentada en el Museo de Arte Contemporáneo de Lima: Gustavo_Buntinx, "Vacío museal. Medio siglo de museotopías peruanas (1966-2006). (Un resumen)", en Alberto Servat et al., Museo del Grabado ICPNA (Lima: Instituto Cultural Peruano Norteamericano), 96-109 (https://www.micromuseo.org.pe/rutas/vacio-museal-2/index.html). En 2008 Micromuseo montó una exposición en homenaje al MTP, curada por Buntinx con Daniel Contreras y Sophia Durand, pero con la decisiva colaboración de Susana Torres: Alteridades. El travestismo en las colecciones de Micromuseo (https://www.micromuseo.org.pe/ rutas/habanaalteridades/index.html).

16 José Carlos Mariátegui, 7 ensayos de interpretación de la realidad peruana (Lima: Amauta, 1984), 243.

17 Gerard Wajcman, La colección, seguido de La avaricia (Buenos Aires: Manantial, 2010), 26. 
"De lo banal resurge el mito" es una frase que propuso la propia Susana Torres para explicar su propio proyecto $^{18}$ (fig. 5). De hecho, en esta colección, la figura de los incas se hace presente en la cotidianidad y consigue adquirir así un cierto carácter mítico. En un notable ensayo, Debord explicó cómo el capitalismo iba adquiriendo, todo él, una dimensión estética y sostuvo que la última forma de la mercancía es su condición de imagen en función de la producción del espectáculo ${ }^{19}$.

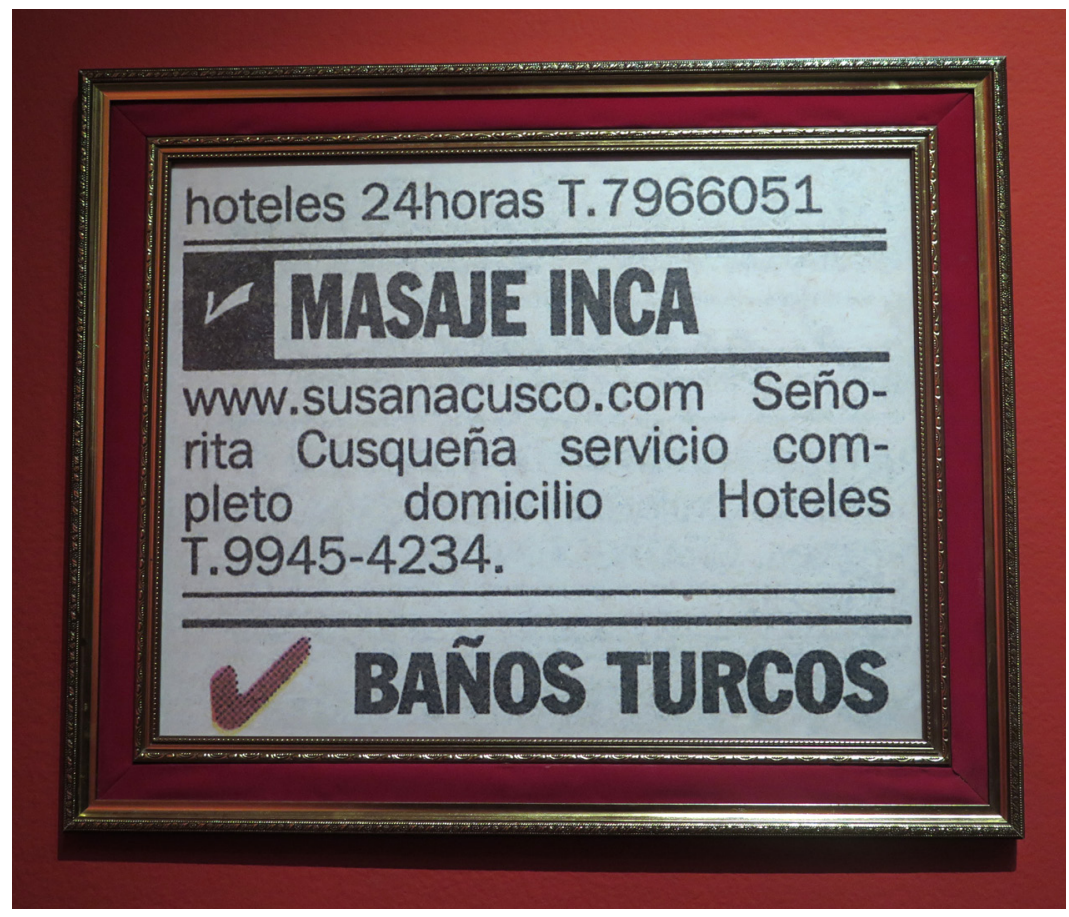

Fig. 5. Susana Torres Márquez, Masaje Inka, 1999. Reproducción infográfica de aviso comercial de periódico de Lima, marco.

Detengámonos aquí: el fetiche es un objeto que ha sido dotado de una fuerza particular y adquiere, desde ahí, un carácter mágico porque en él se proyectan un conjunto de deseos y necesidades diversas. Dada esta condición, se trata de un objeto que captura al sujeto. Bajo el capitalismo, las mercancías se vuelven fetiches porque son sacralizadas como promesas capaces de activar una fascinación sin límites. Sin embargo, desde Freud sabemos bien que un fetiche oculta el miedo a la castración. ¿Qué es entonces lo que estos objetos comerciales ocultan? Sostengamos, nuevamente, que lo que se oculta es la permanente pérdida del sentido de la historicidad o, más bien, lo que se revela es que la única manera en la que ella pueda hacerse presente en la sociedad contemporánea es bajo la simple estetización de una mercancía fetichizada. Como fetiche, la mercancía oculta la historia bajo una nueva forma de hechizo. Desde este punto de vista, la utilización de la palabra "Inca" (o "Inka") es la encargada de construir la fantasía de recuperar una sociedad pre-capitalista, aunque sepamos bien que esa fantasía ya no es posible y "lo que queda es solamente una pura apariencia, la promesa artificial de una sustancia que no se materializa nunca" ${ }^{\prime 20}$. Es decir, bajo el capitalismo, los incas

18 Susana Torres, "El retorno de los inkas (no-retornables)" y "Kiwicha pop", en El retorno de los Inkas (no retornables) (Lima: Micromuseo y Centro Cultural Peruano Británico, 1999), folleto de mano.

19 Guy Debord, La sociedad del espectáculo (Valencia: Pre-textos, 2010), 42.

${ }^{20}$ Slavoj Žižek, El frágil absoluto. ¿Por qué merece la pena luchar por el legado cristiano? (Valencia: Pre-textos, 2002$), 35$. 
se vuelven un puro simulacro de sí mismos si entendemos el simulacro como un proceso repetitivo que convierte a la realidad en una imagen y que la va sustituyendo poco a poco ${ }^{21}$ (figs. 6 y 7 ).

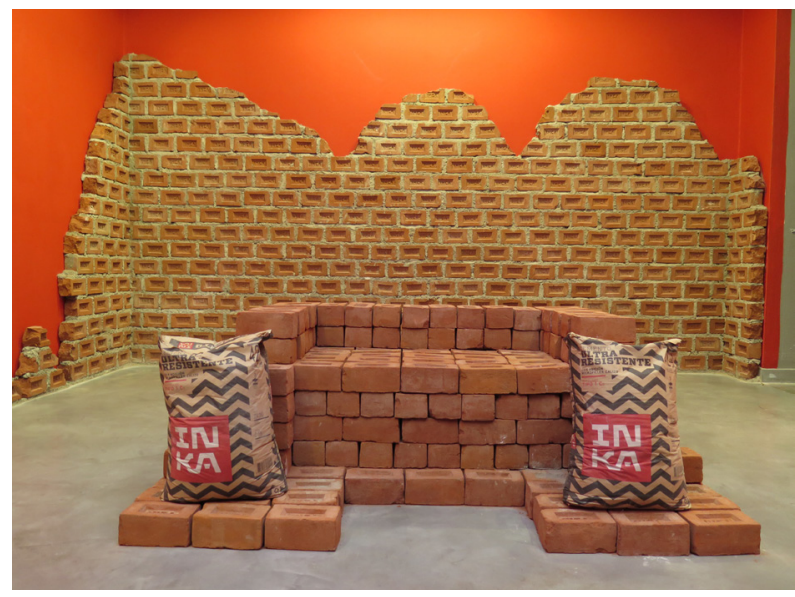

Fig. 6. Susana Torres Márquez, Trono de la Inka, 2014. Ladrillos marca Inca, sacos de cemento marca Inka. Fragmento de instalación integrada a la muestra $R e$ decorando la huaca - Museo Neo Inka IX, Sala Luis Miró Quesada Garland, Lima.

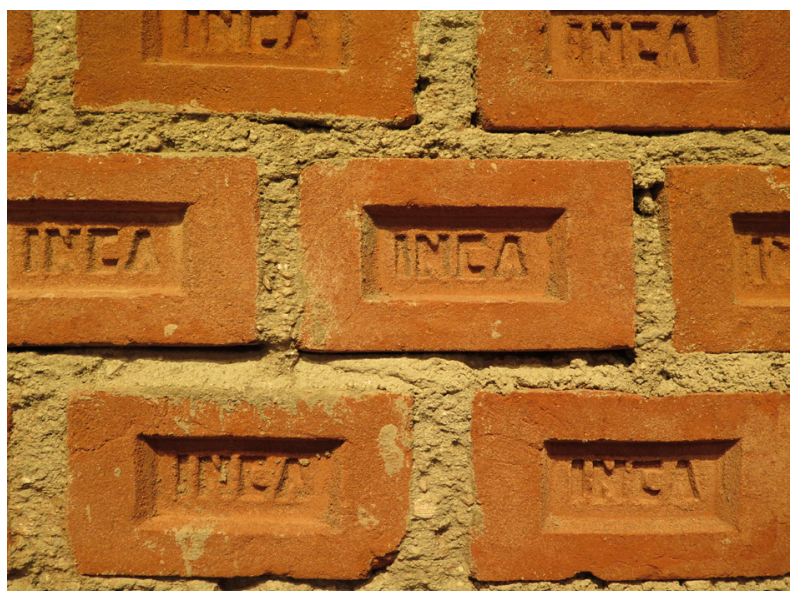

Fig. 7. Susana Torres Márquez, Muro Neo Inka (detalle). Ladrillos marca Inca, cemento marca Inka. Fragmento de instalación integrada a la muestra Re-decorando la huaca - Museo Neo Inka IX, Sala Luis Miró Quesada Garland, Lima.

De todas formas, hay que subrayar que, más allá de todo tipo de exclusiones y traumas, cuando los peruanos hablamos de los incas solemos enorgullecernos. Desde niños, se nos socializa para idealizar al imperio incaico y para festejar que la ciudadela de Machu Picchu haya sido electa como una de las "nuevas" maravillas del mundo ${ }^{22}$. De múltiples maneras, los incas siguen siendo el mito fundacional de la comunidad y el garante de la cultura: aquello que siempre hay que resguardar. El punto, sin embargo, es que la escuela ya no es la única institución encargada de trasmitir ese mito. El mercado ha pasado a cumplir esa función. Desde hace mucho, los niños también llegan a lo incaico por la Inca Kola, empresa que siempre ha contado con memorables campañas publicitarias encargadas de difundir un "nacionalismo sensorial" (es una expresión de la artista). Inca Kola es una Love mark $^{23}$ (figs. 8 y 9).

El "Museo Neo-Inka" es una colección que muestra cómo el capitalismo crea la misma necesidad de estos productos y cómo, en efecto, mantenemos una relación fetichizada con ellos ${ }^{24}$ (fig. 10). Digamos que hoy el capitalismo afirma que el Inca es una imagen solo recuperable en la forma mercancía o, peor aún, como una simple envoltura. Por eso, la función de estos objetos no solo consiste en una supuesta celebración del pasado sino, más bien, en reforzar su pérdida y su muerte. Lo que hoy se impide bajo esa forma estetizada es la posibilidad de un regreso de los incas más allá de las lógicas del valor de cambio. Por eso

21 Jean Baudrillard, Cultura y simulacro (Barcelona: Kairós, 2007).

22 Se trató de un concurso mundial organizado, en el 2007, por la empresa New Open World Corporation en el que votaron más de 100 millones de personas en todo el mundo. El gobierno peruano de ese entonces (cuyo presidente era Alan García) fomentó la votación entre los ciudadanos y celebró oficialmente tal premio.

${ }^{23}$ Ese mito también se ha caído pues, en 1999, Coca Cola compró la Inca Kola y dicho gesto enfrentó a la cultura peruana a una nueva pérdida, o a un nuevo tipo de colonialismo encarnado en el capitalismo trasnacional.

${ }^{24}$ De hecho, en un comentario a Marx, Baudrillard ha explicado cómo las necesidades tampoco son "naturales", sino hábitos construidos culturalmente. Para él, no solo el "valor de cambio" se encuentra fetichizado sino también el "valor de uso" que, como un efecto de la cultura, permite el cambio y la transformación. Baudrillard, Crítica, 148. 
mismo, Buntinx ha afirmado que, en los constantes manejos comerciales de la palabra Inca (o "Inka"), esta colección activa una "melancolía lúdica" o una "tristeza pop": una desconsolada evocación que señala el dramático debilitamiento de las posibilidades siempre latentes de la historia a pesar de una falsa euforia ${ }^{25}$.

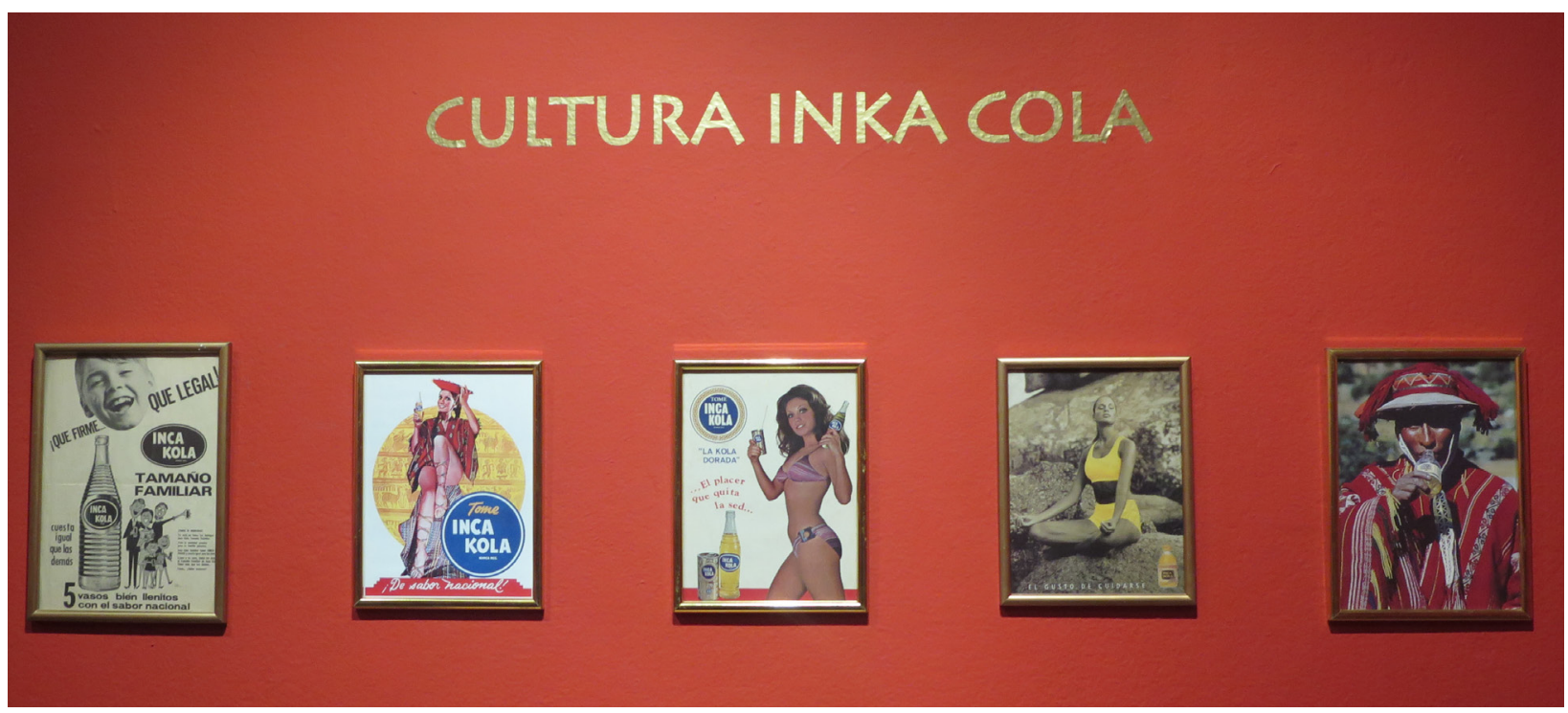

Fig. 8. Susana Torres Márquez, Cultura Inka Cola, 1999-2014. Avisos comerciales de gaseosa marca Inca Kola en revistas de diversas épocas, marcos, cartelas evidenciando su evolución histórica. Fragmento de instalación integrada a la muestra Re-decorando la huaca - Museo Neo Inka IX, Sala Luis Miró Quesada Garland, Lima.

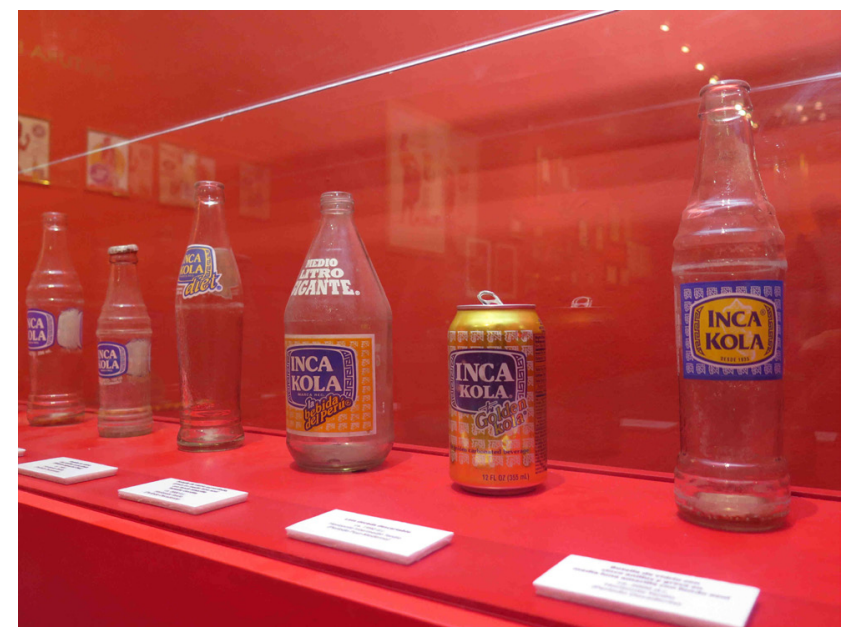

Fig. 9. Susana Torres Márquez, Cultura Inka Cola, 19992020. Envases comerciales de gaseosa marca Inca Kola, vitrina, cartelas evidenciando su evolución histórica. Fragmento de instalación integrada a la muestra Redecorando la huaca - Museo Neo Inka IX, 2014, Sala Luis Miró Quesada Garland, Lima.

\footnotetext{
${ }^{25}$ Conversaciones con Gustavo Buntinx, 2017.
} 


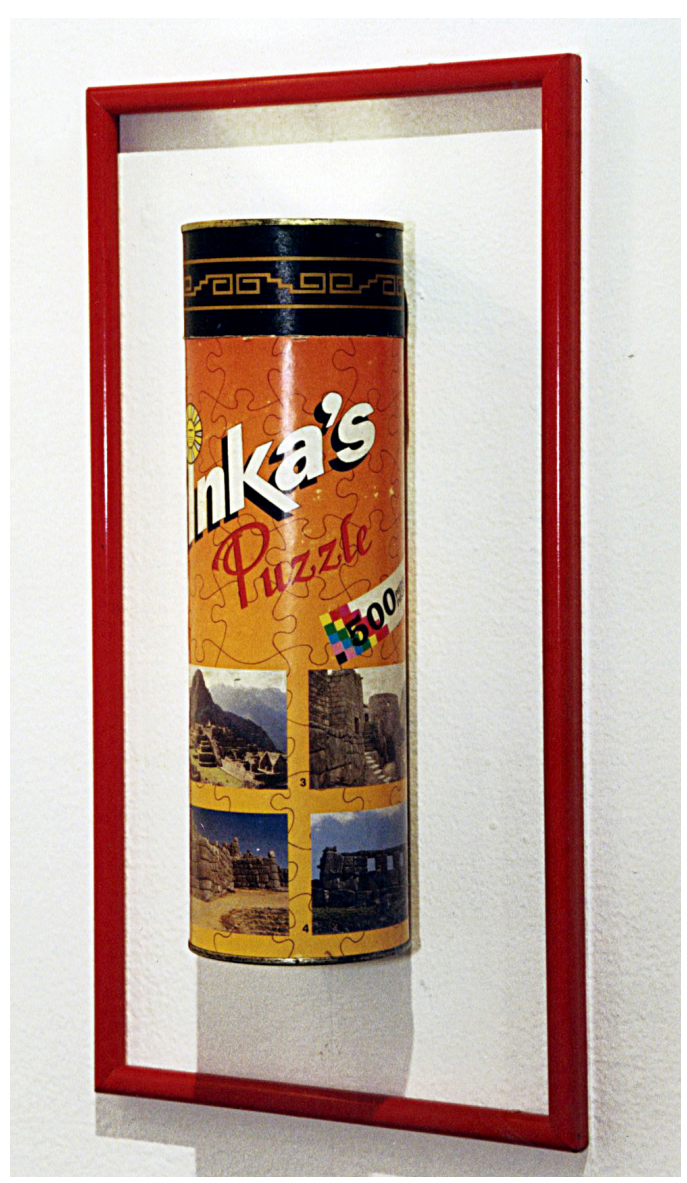

Fig. 10. Susana Torres Márquez, Rompecabezas Inka, 1999-2020. Envase comercial de rompecabezas marca Inka's Puzzle, marco. Fragmento de la instalación Buscando un Inka (El retorno de lo no-retornable), Segunda Bienal Naciona de Lima, 2000.
Digamos, con Žižek ${ }^{26}$, que esta colección muestra un conjunto de objetos que son "sublimes" porque el capitalismo los eleva a la dignidad de "la Cosa" en el marco de complejas dinámicas ideológicas ${ }^{27}$. Es decir, se trata de objetos que prometen la recuperación de la historia, pero en realidad no hacen más que subrayar el goce de su pérdida definitiva. En ese sentido, son objetos sublimes porque hacen visible algo traumático, aunque terminen por evaporar ese mismo trauma. Son sublimes porque, en su cotidianidad, nombran "la falta que están llenando con su presencia", e indican "el fracaso mismo de su representación" 28 . Son "sublimes", finalmente, porque se les ha sustraído todo carácter dramático y porque aluden -fantasmáticamente- a una falsa imagen de reconciliación con la historia.

Expliquemos esto con categorías clásicas: estos objetos son sublimes porque han fusionado la "base" con la "superestructura", vale decir, porque se trata de mercancías que han circulado como valores de cambio, pero lo han hecho radicalizando su semblante o, mejor dicho, lo han hecho jugando con el semblante de la historicidad. Dramatizando y desdramatizando la historia, los objetos de esta colección se presentan como una pregunta ya no solo por las nuevas dinámicas del capitalismo sino por formas nuevas de imaginación de la comunidad. Toda colección -lo ha sostenido Wajcman- crea una colectividad que se unifica alrededor del objeto ${ }^{29}$. Dicho de otra manera: si hoy la nación es una especie de suplemento imaginario frente a la desintegración promovida por las lógicas del capital ${ }^{30}$, los objetos del "Museo Neo Inka" son "sublimes" porque encaran al presente (y al pasado) con un límite doloroso: muestran que en la cultura hay algo que falta, pero buscan ansiosamente suplantar esa falta, creando un fetiche y activando un ritual en torno a esa falta a

fin de resignificarla. La palabra Inca (o Inka) es el significante encargado de cumplir esa misión en el contexto del desarrollo del capitalismo peruano.

Notemos, además, que la importancia simbólica de esta colección reside en recordar cómo, bajo el capitalismo, hemos terminado sometidos a un conjunto de fuerzas externas que nos dominan. En realidad, no es que creamos directamente en las propiedades mágicas de la palabra "Inca" (o "Inka"), sino que participamos en las interacciones cotidianas como si creyéramos. Como lo ha explicado Žižek, la nuestra es una sociedad donde, de manera "interpasiva", las cosas han comenzado a "creer" en lugar de nosotros ${ }^{31}$. Todo

${ }^{26}$ Slavoj Žižek, El sublime objeto de la ideología (México D.F.: Siglo XXI, 1992), 194.

${ }^{27}$ La "cosa" lacaniana refiere a una dimensión de lo Real nunca capturada por la cultura. Es una especie de exterior radical investido como una huella del paraíso perdido. Jacques Lacan, La ética del psicoanálisis. Seminario 7 (Buenos Aires: Paidós, 2005); Slavoj Žižek, Mirando al sesgo. Una introducción a Jacques Lacan a través de la cultura popular (Buenos Aires: Paidós, 2000).

28 Žižek, El sublime objeto, 264.

29 Wajcman, La colección, 50.

30 Slavoj Žižek, "Multiculturalismo".

31 Slavoj Žižek, "La interpasividad y sus vicisitudes”, en El acoso de las fantasías (México D.F.: Siglo XXI, 1999$), 125$. 
fetiche es, en efecto, un objeto que funciona a pesar de nuestra aparente distancia con él. Desde ahí, esta colección permite observar cómo las cosas (y no las personas) son las que hoy creen en el poder de los incas, vale decir, queda claro cómo desplazamos hacia las cosas la capacidad de creer en lugar de nosotros ${ }^{32}$. Explicando las colecciones de Fuchs, Benjamin lo fraseó así:

El concepto de cultura comporta a su entender un rasgo fetichista en tanto cifra de hechuras a las que se considera independientes, no del proceso de producción en el que surgieron, pero sí de aquel en el que perduran ${ }^{33}$.

Resumamos: el "Museo Neo Inka" se sumerge en lo cotidiano y en lo banal, y hurga en dichos espacios para encontrar ahí viejas y nuevas pulsaciones de la historia. La artista Susana Torres es la constructora de este nuevo archivo. Como arqueóloga, va en busca de verdaderas reliquias en tiendas y supermercados. Como etnógrafa, deja constancia de las maneras en la que los restos del pasado se actualizan en el presente. Y, como artista, propone una nueva representación de la cultura peruana más allá de los relatos a los que la historia oficial nos tiene acostumbrados. Desde la franca opción por situarse dentro y fuera del arte, el "Museo Neo Inka" marca la condición del presente, de la propia escena artística y produce una imagen estética (y política) sobre la imaginación de la comunidad.

Retomando un viejo gesto dadaísta, el objetivo del "Museo Neo Inka" consiste en sacar de la circulación a un conjunto de objetos cotidianos a fin de re-auratizarlos exigiendo una nueva mirada sobre ellos $^{34}$. No se trata solamente de buscar nuevas definiciones sobre el arte y de jugar con sus límites, sino de instalarles una nueva condición aurática. En efecto, en esta colección vemos mercancías, pero, al quedar inscritas en la serie, son capaces de activar resonancias diversas. Si, como hemos dicho, toda colección se estructura desde una falta, y si cada nuevo objeto es un intento por llenarla, el "Museo Neo Inka" busca llenar el lugar vacío que tiene la historicidad en los tiempos del capitalismo avanzado. Mostrando su doble faz (escenificar la mercancía, construir un semblante utópico), esta colección escenifica, con ironía, pero también como drama, las dinámicas culturales que definen a nuestra contemporaneidad.

La artista, en suma, reconoce muy bien el tipo de sociedad en la que vivimos, pero reconoce que existe una rendija digna de aprovechar. Lo cierto es que la mercancía nunca puede totalizarlo todo, deja algunos desechos y sabemos bien que el arte (desde las vanguardias) no tiene problemas en trabajar con ellos. “¿Esto es arte o basura?”, le preguntó uno de sus hijos a Susana Torres cuando en la cocina de la casa encontró estos objetos con la marca "Inca" (figs. 11 y 12).

"El pasado es útil y necesario a condición de que tengamos algún control sobre él y no permitamos que sus fantasmas nos cierren el horizonte" sostuvo Alberto Flores Galindo hace ya algunas décadas. ${ }^{35}$ Si esta colección nos atrae, vale decir, si algo de la ironía y del brillo de sus objetos nos seduce es por la capacidad simultánea para cumplir tanto una función ideológica como para vehiculizar fantasías desesperadamente utópicas ${ }^{36}$. Esta es, en efecto, una colección que nos acerca y nos aleja tanto de la historia como del propio objeto artístico pues en ella ambos retornan como farsa. Con un gesto que es lúdico y agónico al mismo tiempo, el "Museo Neo-Inka" muestra la estetización de la mercancía y la mercantilización del presente haciendo más visible, sin complejos, esta nueva condición histórica, colocándola como imagen colectiva y representando, sin miedo, las actuales lógicas de la mercancía para intentar horadarlas desde su propia interioridad ${ }^{37}$.

32 Slavoj Žižek, El sublime objeto, 50.

33 Walter Benjamin, "Historia y coleccionismo: Eduard Fuchs", en Discursos interrumpidos I (Buenos Aires: Taurus, 1989), 101.

${ }^{34}$ Agradezco los comentarios de Mijail Mitrovic en este punto y en otros.

35 Alberto Flores Galindo, "La utopía andina: esperanza y proyecto”, en Tiempo de plagas (Lima: El caballo Rojo, 1988 ), 253.

36 Jameson, "Reificación y utopía", 76.

37 Benjamin, "Historia y coleccionismo", 106. 


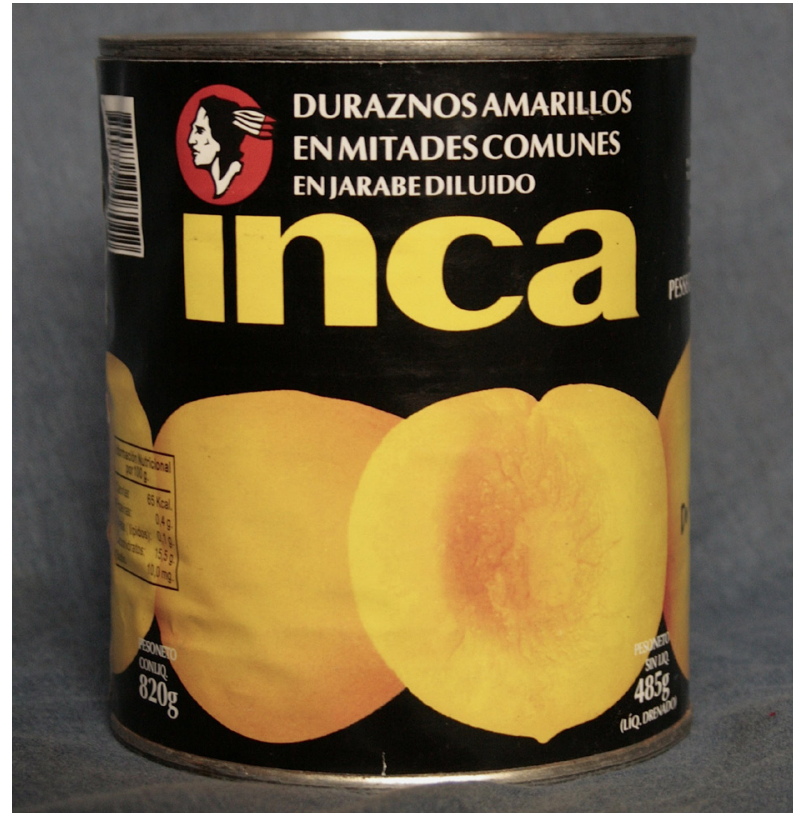

Fig. 11. Susana Torres Márquez, Duraznos Inka, 1999. Envase comercial de duraznos marca Inca.

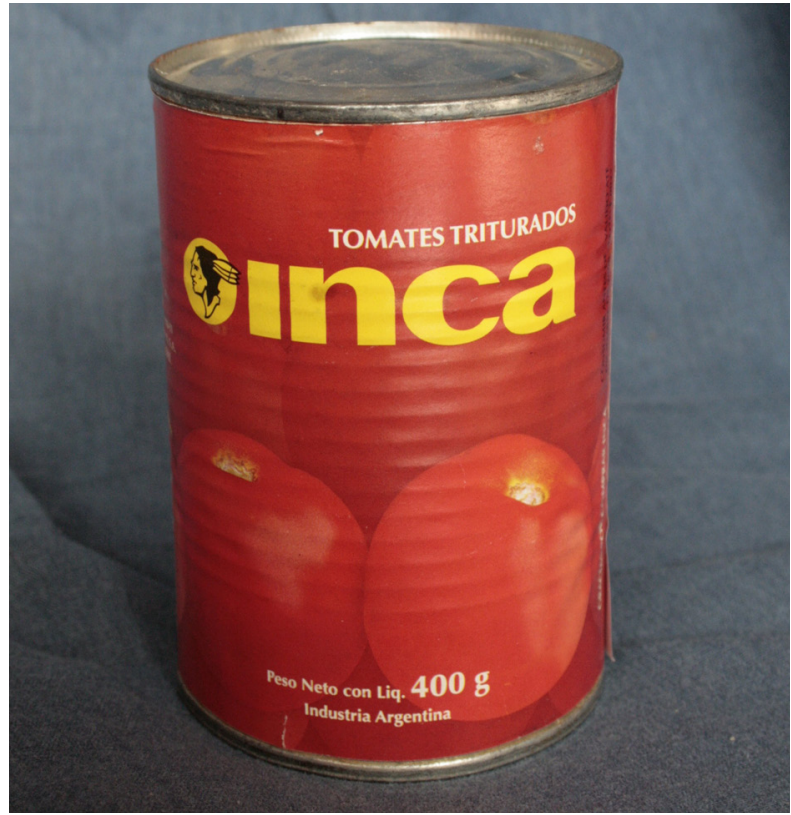

Fig. 12. Susana Torres Márquez, Tomates triturados Inka, 1999. Envase comercial de pasta de tomate marca Inca.

Marx, sostuvo que a la mercancía había que entenderla como un producto "endemoniado, rico en sutilezas metafísicas y reticencias teológicas"38. En los últimos años, Susana Torres y Gustavo Buntinx no se han cansado de repetir, una y otra vez, una famosa frase de santa Teresa de Jesús: "Dios se mueve entre los cacharros" 39 . Es exacto: la mercancía -y todo el sistema del arte- opera entre lo más radiante (y vil) de la historia.

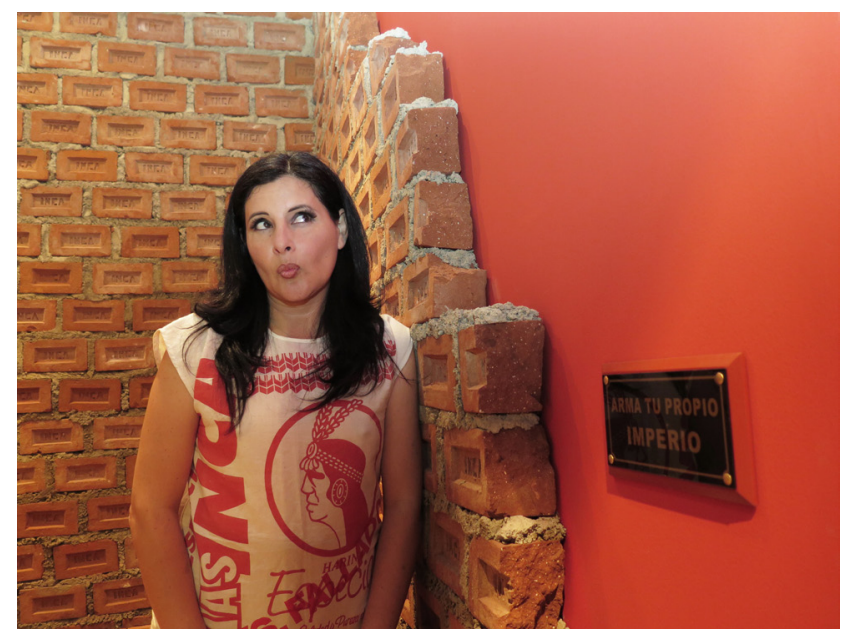

Fig. 13. Susana Torres Márquez caracterizada en la muestra Arma tu propio imperio. Museo Neo Inka X, Feria Art Lima, 2014.

38 Marx, "El carácter fetichista", 87.

39 Torres, El retorno de los Inkas; Gustavo Buntinx, Lo impuro y lo contaminado. Pulsiones (neo)barrocas en las rutas de Micromuseo ("al fondo hay sitio") (Lima: Micromuseo, 2007); libro que acompaña la exposición de mismo nombre en la Bienal de Valencia - Sao Paulo. Versión ampliada en: https://www.micromuseo.org.pe/publicaciones/loimpuroylocontaminado.html 
VÍCTOR VICH es doctor en literatura hispanoamericana por Georgetown University, EEUU. Es autor de ocho libros entre los que destacan: Poéticas del duelo: ensayos sobre arte, memoria y violencia política (2015), Desculturizar la cultura: la gestión cultural como forma de agencia política (2014) y Poetas peruanos del siglo XX. Lecturas críticas (2018). Ha sido profesor invitado en diversas universidades como Harvard, Berkeley y Madison en los EEUU. Ha sido miembro de Comité Directivo del Consejo Latinoamericano de Ciencias Sociales (CLACSO 2007-2009), asesor de políticas culturales de la Municipalidad de Lima y fue miembro del equipo curatorial del Lugar de la Memoria en el Perú (LUM). En el 2009, ganó la beca Guggenheim y en el 2014 la beca Tinker. Actualmente, es director de la Maestría en Estudios Culturales en la Pontificia Universidad Católica y profesor en la Escuela Nacional Superior de Bellas Artes en el Perú.

Email: vvich@pucp.pe

Código ORCID: https://orcid.org/0000-0003-4192-6873 